\title{
EFFECTS OF DIFFERENT LEVELS OF PROTEIN AND ENVIRONMENTAL STIMULATION ON THE BEHAVIOR OF YOUNG RATS TESTED IN THE ELEVATED PLUS-MAZE
}

TANIA REgINA RIUL

PATRíCiA. S. Almeida

ANDRÉA. F. CARVALHO

SebAstião de SOUSA ALMEIDA

LUIZ MARCELLINO DE OLIVEIRA ${ }^{\dagger}$

UniVERSIDADE de SÃo PaUlo, São PaUlo, BRASIL

\begin{abstract}
The interaction between the effects of different levels of protein malnutrition and environmental stimulation was investigated in young male rats in the elevated plus-maze (EPM). Litters (dam plus 6 male and 2 female pups) were fed a 16\% (Control: C), 10\% (Malnourished: M10) or 6\% (Malnourished: M6) protein diet. Half of the litters were daily exposed to additional stimulation (CS, MS10 or MS6), while the other half was maintained in normal rearing conditions (CN, MN10 or MN6). The stimulation (handling) consisted of holding the rat in one hand and gently touching the dorsal part of the body with the fingers for $3 \mathrm{~min}$. On the 22 nd day of life (weaning), two male pups from each group were tested in the plus-maze. Two male pups continued to receive the same diet their mothers, and other two were fed a non-purified lab chow diet until 35 days of age when they were tested in the plus-maze (LN, LS, LN10, LS10, LN6 and LS6 groups). Results showed that environmental simulation increased open arms exploration both at 22 and 35 days of age, indicating an anxiolytic effect of this procedure. Younger rats (22 days of age) explored significantly more the open arms of the maze as compared with older rats (35 days of age), indicating an increase in anxiety with age. M6 animals showed significantly higher percentages of open arm entries and less frequent attempts to enter open arms in the maze as compared with C and M10 animals. These results suggest that even a short period of protein deficiency can produce alterations in the emotional response of rats in the elevated plus-maze. In addition, the data demonstrated that protein deficiency more severe than $10 \%$ is necessary to produce behavior alterations in the EPM test.
\end{abstract}

Keywords: Age, Anxiety, Environmental stimulation, Impulsiveness, Plus-maze test, Protein malnutrition levels.

Correspondence regarding this article should be directed to:Avenida Bandeirantes, 3900, 14040-901, Ribeirão Preto - SP, Brazil.

* Originally published in Nutritional Neuroscience, Vol. 1, pp. 295-303, 1998. Reproduced with permission. 
Early protein malnutrition and environmental stimulation have been reported to produce morphological and neurochemical changes in the central nervous system, as well as long-term alterations in behavioral expression (Denenberg, 1969; Morgane et al., 1993; Levistsky and Strupp, 1995; Renner and Rosenzweig, 1987).

Since malnourished populations live in a low stimulatory environment, the behavioral consequences of malnutrition could be not only due nutritional deficiency but also to a poor environment (Barnes, 1976; GranthamMcGregor, 1995).

There is clear evidence that environmental stimulation may reduce or modify the behavioral effects of early malnutrition. However, the exact mechanism by which early malnutrition and environmental stimulation interact to produce long-lasting changes in behavior are not fully understood.

Rats submitted to environmental stimulation change their behavioral reaction to a new environment. The behavioral alterations include increases in open arms exploration in the elevated plus-maze (EPM) and higher exploration of the light-dark transition test (Santucci et al., 1994). An increase in the number of rears in the open field (Rocha and Mello, 1994), a decrease in the latency to eat in a new environment (Bodnoff et al., 1987), and a decrease in the defecation associated with an increase on head-dipping behavior have been demonstrated in the open field and hole-board tests (Fernández-Teruel et al., 1992).

In addition, is has been consistently reported that protein or protein-calorie malnutrition imposed booth during the pre-and post-natal periods cause long-lasting effects on EPM exploration in adult life. Previously early malnourished rats showed increased open arms exploration in the EPM when tested at 70 days of age, suggesting a higher anxiety and/or higher impulsiveness caused by malnutrition (Almeida et al., 1991; 1993; 1994; 1996; Moreira et al., 1997).

The EPM is a well known animal model of anxiety based on spontaneous exploratory behavior, avoiding the use of painful aversive stimuli, water, and food deprivation or training (Pellow et al., 1985). It is a sensitive producer for the identification of the anxiolytic and anxiogenic effects of drugs (Pellow et al., 1985; Rodgers et al., 1977), as well as of the effects of diet and environmental stimulation procedures (Almeida et al., 1991; Santucci et al., 1994; Moreira et al., 1997).

Thus, higher number of visits or time spent in the arms indicates lower anxiety or even high degree of exploratory behavior (Pellow et al., 1985).

Most literature data describe only the long-lasting effects of early malnutrition or environmental stimulation on the EPM, with previously malnourished rats being tested in adult life after a prolonged period of nutritional recovery (Almeida et al., 1991; 1993; 1994; 1996; Santucci et al., 1994; Moreira et al., 1997; Laino et al., 1993).

Thus, the aim of the present study was to investigate in the EPM the effects of both different levels of protein malnutrition and environmental stimulation during early stages of development of the rats (22 and 35 days of age), since during early development the potential susceptibility to nutritional deficiency mal be increased. This experimental protocol will also allow us to determine the effects of concurrent malnutrition ( 22 days of age), as well as the effects of previous malnutrition after a short nutritional recovery period (35 days of age).

\section{METHODS}

\section{Subjects}

Female virgin Wistar rats from the animal house of the Ribeirão Preto Campus of the University of São Paulo, aged approximately 90 days were mated in our laboratory. Within $24 \mathrm{~h}$ after parturition, litters were formed with 8 pups (6 males and 2 females) taken randomly from a large pool of pups. The litters were randomly assigned to isocaloric diets containing $16 \%$ (Control: C), 10\% (Malnourished: M10) or 6\% protein (Malnourished: M6). The source of protein was casein and the diets were prepared according to Santucci et al. (1994) Rocinholi et al. (1997) and offered ad libitum to the litters. Half of the litters in each diet condition were exposed daily to an additional $3 \mathrm{~min}$ of stimulation (CS, MS10 or MS6). The stimulation (handling) consisted of holding the animal in one hand gently touching the dorsal part of the anima's body with the fingers. The other half of the litters was maintained under normal rearing conditions without additional stimulation (CN, MN10 or MN6). Since stimulation of all litters took approximately $24 \mathrm{~min}$, the non-stimulated pups were separated from their mother for an equivalent period of time. Environmental stimulation was applied from birth to weaning ( 22 days of age).

After weaning, the male pups of each litter were divided into three groups. The first was tested in the maze on the $22^{\text {nd }}$ day of age (CN, CS, MN10, MS10, MN6 and MS6). The second group was kept under the same diet conditions and tested at 35 days of age. Finally, the third group received a non-purified (Purina - Brazil) commercial diet containing $23 \%$ of protein (LN, LS, LN10, LS10, LN6 and LS6) from 22 to 35 days of age, when they were tested. During this phase the pups were individually maintained in metal cages $(25 \times 19 \times 15 \mathrm{~cm}-$ Funbec - Brazil). Thus, a total of 12 groups were used defined as: $\mathrm{CN}=16 \%$ protein non-stimulated control group $(n=24)$; $\mathrm{CS}=16 \%$ protein stimulated control group $(n=24) ; \quad \mathrm{MN} 10=10 \%$ protein non-stimulated malnourished group $(\mathrm{n}=10-12) ; \mathrm{MS} 10=10 \%$ protein stimulated malnourished group $(\mathrm{n}=12) ; \mathrm{MN} 6=6 \%$ protein non-stimulated malnourished group $(\mathrm{n}=12)$; MS6 $=6 \%$ protein stimulated malnourished group $(\mathrm{n}=12-$ $13) ; \mathrm{LN}=16 \%$ protein non-stimulated group during lactation and non-stimulated group during lactation and non-purified lab chow diet from 22-35 days of age ( $\mathrm{n}=$ $24) ; \mathrm{LS}=16 \%$ protein stimulated group during lactation and non-purified lab chow diet from 22-35 days of age $(\mathrm{n}=24) ; \mathrm{LN} 10=10 \%$ protein non-stimulated group during lactation and nonpurified lab chow diet from 22-35 days of age $(n=12) ; \operatorname{LS} 10=10 \%$ protein stimulated group during lactation and non-purified lab chow diet from 22-35 days of age $(n=12) ; \mathrm{LN} 6=6 \%$ protein non-stimulated group during lactation and nonpurified lab chow diet from 22-35 
days of age $(n=12)$; LS6-6\% proteinstimulated group during lactation and non-purified lab chow diet from 2235 day of age $(n=13)$. The animals were weighed once a week and maintained on a 12-hour light-dark cycle (lights on at 6 AM.).

These conditions meet the standards for the care of laboratory animals as outlined in the Guide for the Care and Use of Laboratory Animals (NRC 1996).

\section{Apparatus}

The EPM was made of wood and consisted of two open arms $(50 \times 10 \mathrm{~cm})$ opposite to each other, crossed by two enclosed arms $(50 \times 10 \times 40 \mathrm{~cm})$, with an open roof. The maze was elevated $50 \mathrm{~cm}$ from the ground floor, as described by Pellow et al. (1985). The experimental sessions were recorded with a camera (Sony, model WatchCam) linked to a VCR (Mitsubishi, model HS338M), and a TV (Philips, model TX) in an adjacent room. Fluorescent ceiling white light (40W) provided illumination in the test room.

\section{Procedure}

The animals were placed individually in the center of the maze facing an enclosed arm, and allowed to explore for $5 \mathrm{~min}$. The tests were conducted between 7:00 and 8:00 AM. The maze was cleaned videotapes were later analyzed by an experimenter and the following behavioral categories were recorded: (a) Percentage of open arm entries (number of open arm entries/total number of open + closed arm entries x 100); (b) Percentage of time spent in open arms (time in open arms/total time in open + closed arms x 100); (c) closed arm entries; (d) number of attempts to enter open arms (entering an open arm with up to three paws and returning to the central platform or closed arm) and $€$ number of closed arm returns (exiting a closed arm up to three paws and returning to the same arm).

\section{Statistical Analyses}

The body weights of pups were treated by a twofactor (diet and environmental stimulation) analysis of variance (ANOVA). Behavioral categories recorded in the EPM were submitted to a three-factor (diet, environmental stimulation and age) ANOVA. The percentage of open arms entries, attempts to enter open arms and closed arms returns were subjected to square root transformation to normalize the data. The post-hoc analyses were conducted using Newman-Keuls' test. The Statistica statistical package was used and an alpha level of $\mathrm{p}<0.05$ was considered to be significant.

\section{Body Weights}

\section{RESULTS}

Well-nourished animals showed a higher body weight at 22 days of age, as evidenced by a significant effect of diet $(\mathrm{F}(2,95)=351.16, \mathrm{p}<0.001)$. Post-hoc analysis showed that $\mathrm{C}$ animals $(43.83 \pm 0.85 \mathrm{~g})$ were heavier than M10 (22.79 $\pm 0.81 \mathrm{~g})$ animals and M10 animals were heavier than M6 animals (14.8 \pm 0.51$)$ $(\mathrm{p}<0.05)$. The significant effect of diet was also shown at
35 days of age $(\mathrm{F}(5,182)=370.84, \mathrm{p}<0.001)$. Post-hoc analysis showed that the $\mathrm{C}$ groups $(120.37 \pm 1.78 \mathrm{~g})$ and $\mathrm{L}$ groups $(125.44 \pm 1.99 \mathrm{~g})$ were heavier than the other nutritional groups $(\mathrm{p}<0.05)$. In addition, The L10 groups $(88.05 \pm 2.51 \mathrm{~g})$, were heavier than the L6 groups $(64.38 \pm$ $2.0 \mathrm{~g}$ ) which in turn were heavier than the M10 groups $(57.13 \pm 2.64 \mathrm{~g})$, and the latter were heavier than the M6 groups $(20.36 \pm 0.9 \mathrm{~g})(\mathrm{p}<0.05)$.

\section{Elevated Plus-Maze Behaviors}

As illustrated in Figure 1, ANOVA indicated a significant overall effect of diet on the percentage of open arms entries both at 22, F $(2,179)=6.37, \mathrm{p}<0.01$, and 35 , $\mathrm{F}(5,179)=9.5, \mathrm{p}<0.001$, days of age. Post-hoc analyses showed that animals of the M6 groups had a higher percentage of open arms entries than animals of the $\mathrm{C}$ groups $(p<0.05)$ at 22 days of age. At 35 days of age. At 35 days of age, post-hoc analyses showed a higher percentage of open arms entries in M6 groups $(p<0.05)$. In addition, M10 animals showed a higher percentage of open arm entries as compared with all $\mathrm{L}$ groups $(\mathrm{p}<0.05)$. A significant overall effect of environmental stimulation on the percentage of open entries was
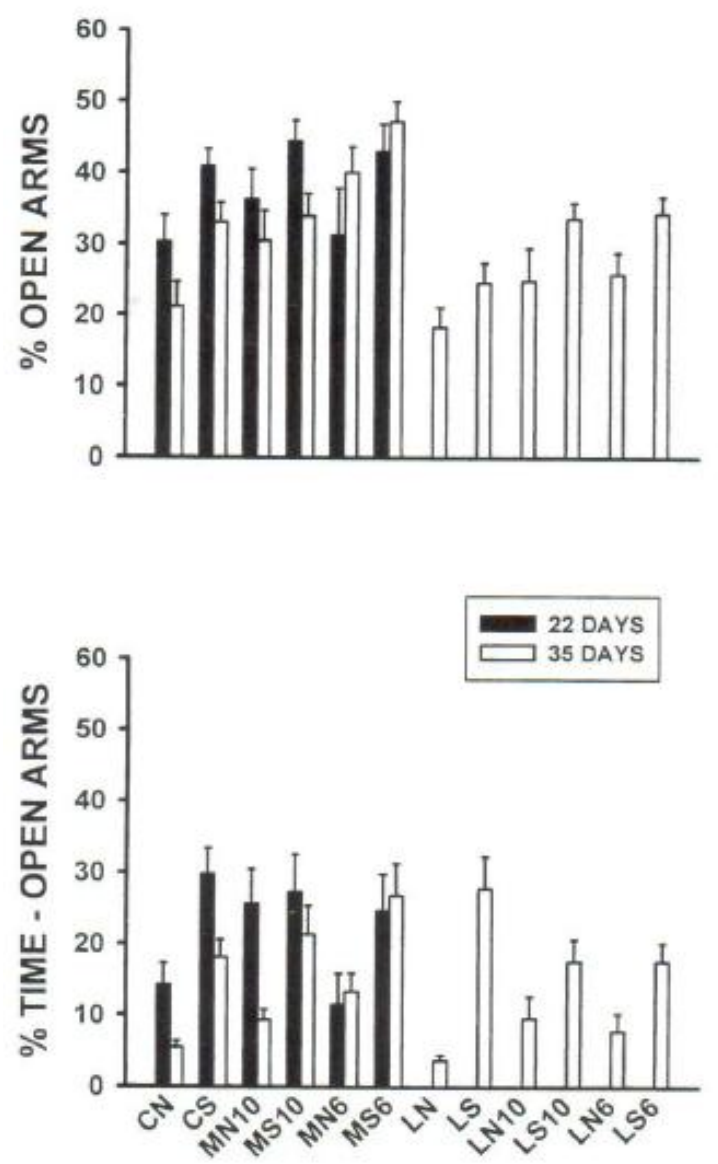

\section{GROUPS}

Figure 1 percentage of open arm entries (upper part) and percentage of time spent in the open (lower part) of the EPM for 22 days (filled bars) and 35 day (open bars) old rats. Each bar represents the man \pm S.E.M $\mathrm{CN}=16 \%$ protein non-stimulated control group $(n=24) ; C S=16 \%$ protein stimulated control 
$(\mathrm{n}=24) ; \mathrm{MN} 10=10 \%$ protein non-stimulated malnourished group $(\mathrm{n}=10-12) ; \mathrm{MS} 10=10 \%$ protein stimulated malnourished group $(\mathrm{n}=12) ; \mathrm{MN} 6=6 \%$ protein non-stimulated malnourished group $(\mathrm{n}=12) ; \mathrm{MS} 6=6 \%$ protein stimulated malnourished group $(\mathrm{n}=12$ 13); $\mathrm{LN}=16 \%$ protein non-stimulated group during lactation and lab chow diet from $22-35$ days of age $(n=24) ; L S=16 \%$ protein stimulated group during lactation and lab chow diet from 22-35 days of age $(n=24) ; \mathrm{LN} 10=10 \%$ protein non-stimulated group during lactation and lab chow diet from 22-35 days of age $(\mathrm{n}=12) ; \mathrm{LS} 10=10 \%$ protein stimulated group during lactation and lab chow diet from $22-35$ days of age $(n=12)$; $L N 6=6 \%$ protein non=stimulated group during lactation and lab chow diet stimulated group during lactation and lab chow diet from 22-35 days of age $(n=13)$.

Also observed both at $22, \mathrm{~F}(1,179)=15.15$, $\mathrm{p}<0.001$, and $35, \mathrm{~F}(1,179)=14.34, \mathrm{p}<0.001$, days of age. The stimulated animals showed a higher percentage of open arm entries than non-stimulated animals at both at 22 and 35 days of age. Finally, a significant diet $x$ day interaction $\mathrm{F}(2,179)=4.59$, $\mathrm{p}<0.01$ on the percentage of open arm entries was observed. Post-hoc analyses also showed that M6 groups tested at 35 days of age had a higher percentage of open arms entries than the M10 and $\mathrm{C}$ groups tested at the same age $(\mathrm{p}<0.05)$.

As illustrated in Figure 1, there was a significant overall effect of environmental stimulation both at 22 , $\mathrm{F}(1,179)=37.3, \quad \mathrm{p}<0.001, \quad$ and 35 days of age, $\mathrm{F}(1,179)=60.42, \mathrm{p}<0.001$, with the stimulated animals exhibiting higher percentages of time spent in the open arms than non-stimulated animals. A significant overall effect of age, $\mathrm{F}(1,179)=5.54, \mathrm{p}<0.05$, was also demonstrated animals. A significant overall effect of age, $\mathrm{F}(1,179)=5.54$, $\mathrm{p}<0.05$, was also demonstrated, with younger rats (22days) spending a higher percentage of time in the open arms than older rats (35days). A significant diet $x$ day interaction, $F(2,179)=4.13, p<0.05$, on the percentage of open arm entries was also observed. However, the post-hoc analyses did not show any differences among the groups.

As illustrated in Figure 2, ANOVA indicated a significant overall diet effect, $F(2,179)=3.7, p<0.05$, on the number of closed arm entries, with M6 animals entering the closed arms significantly less than C and M10 animals at 22 days of age $(\mathrm{p}<0.05)$. There was also a significant overall effect of age, $F(1,179)=10.4$, $p<0.01$, with a higher number of closed arm entries observed in older (35days) than in younger animals (22 days). There was also significant overall effect of environmental stimulation both at $22 \quad(\mathrm{~F}(1,179)=16.67, \quad \mathrm{p}<0.001) \quad$ and $(\mathrm{F}(1,179)=26.87, \mathrm{p}<0.001)$ days of age, with stimulated animals entering the closed arms more than non-stimulated animals. A diet $\mathrm{x}$ environmental stimulation $\mathrm{x}$ age interaction $\mathrm{F}(2,179)=3.8$, $\mathrm{p}<0.05$ on closed arm entries was also demonstrated. Post-hoc analyses showed that at 35 days

Of age the MS10 group made more closed arm entries than all other groups, except the CS group $(\mathrm{p}<0.05)$. In addition, MN10 tested at 22 days of age and CS, MS10 and MS6 groups tested at 35 days of age showed more closed arms entries than the MN6 group tested at 22 days of age $(\mathrm{p}<0.05)$.
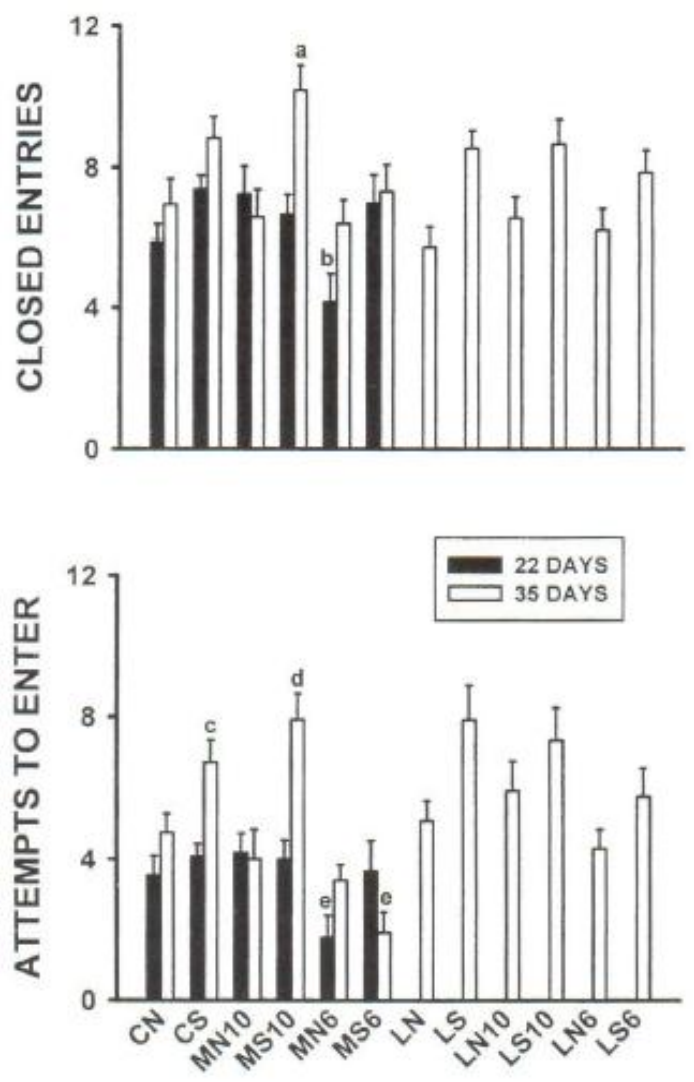

\section{GROUPS}

Figure 2 Number of closed arm entries (upper part) and number of attempts to enter open arm (lower part) of the EPM for 22 day (filled bars) and 35 days (open bars) old rats. Each bar represents the mean \pm S.E.M. See legend to Figure 1 for details. (a)MS10 at 35 days of age $>$ of all other groups except CS, p <0.05; (b) MN6 at 22 days of age $<\mathrm{MN} 10$ at 22 days of age, LS, LS10 and LS6, $\mathrm{p}<0.05$; (c) LS $>\mathrm{CN}$ and M6 at 22 days of age, $\mathrm{p}<0.05$; (d) LS10 $>$ all other groups, except LS, $\mathrm{p}<0.05 ; €$ MN6 and MS6 at 22 days of age $<$ all other groups, $\mathrm{p}<0.05$.

As illustrated in Figure 2, there was a significant overall effect of diet at both $22, \mathrm{~F}(2,183)=$ $21.96, \mathrm{p}<0.001$, and $35, \mathrm{~F}(5,179)=8.03$, $\mathrm{p}<0.001$, days of age on the number of attempts to enter open arms. Post-hoc analysis showed that M6 groups exhibited lower frequencies of attempts to enter open arms as compared with $\mathrm{C}$ and M10 animals at 22 days of age $(p<0.05)$. At 35 days of age, post-hoc analysis showed that M6 animals exhibited lower frequencies of attempts to enter open arms than C, L, M10 and L6 animals $(\mathrm{p}<0.05)$. There was also a significant overall effect of stimulation at both $22, \mathrm{~F}(1,183)=7.54$, $\mathrm{p}<0.01$, and $35, \mathrm{~F}(1,179)=8.56, \mathrm{p}<0.01$, days of age, with stimulated animals showing higher number of attempts to enter open arms as compared with non-stimulated animals at both ages. A significant overall effect of age, $\mathrm{F}(1,183)=10.17, \mathrm{p}<0.01$, on the attempts to enter open arms was also observed. Post-hoc analysis showed that older animals (35days) presented higher number of attempts to enter open arms than younger animals (22 days). 
A significant diet $\mathrm{x}$ environmental stimulation interaction $(\mathrm{F}(5,179)=3.53, \mathrm{p}<0.01)$ on the attempts to enter open arms was also observed. Post-hoc analysis showed that animals of the M6 groups exhibited lower that animals of the M6 groups exhibited lower frequencies than the animals of all other groups $(\mathrm{p}<0.05)$. Animals of the MS10, LS and LS10 groups showed higher frequencies than MN6 animals $(\mathrm{p}<0.05)$ and MS10 and LS animals showed higher frequencies than MN10 animals ( $\mathrm{p}<0.05)$.

There was also a significant diet $\mathrm{x}$ stimulation $\mathrm{x}$ day interaction $(\mathrm{F}(2,183)=10.08, \mathrm{p}<0.001)$ on the attempts to enter open arms. Post-hoc analysis showed that animals from the CS group tested at 35 days of age presented higher frequencies of attempts to enter open arms than all other groups, except for the CS animals tested at 35 days $(\mathrm{p}<0.05)$. Finally, the MN6 and MS6 groups tested at 22 days of age showed lower frequencies of attempts to enter open arms than all other groups $(\mathrm{p}<0.05)$.

There was only a significant effect of day $(\mathrm{F}(1,183)=23.13, \mathrm{p}<0.001)$ on the frequency of closed arms returns, with animals at 35 days $(1.13 \pm 0.14)$ showing significantly higher frequencies of this behavior than animals at 22 days $(0.42 \pm 0.08)$ of age.

\section{DISCUSSION}

The higher percentages of open arms exploration observed in younger malnourished rats (22 and 35 days of age) in the present study extend previous data obtained in our laboratory with adult animals (70 days of age) submitted to malnutrition during the gestation, lactation and post lactation periods (Almeida et al., 1991; 1993; 1994; 1996; Moreira et al., 1997). These data show that even a short period of nutritional insult can produce alterations on the behavior of rats submitted to the EPM, in the same direction as those produced by longer periods of nutritional deficiency. Thus, early protein malnutrition led to behavioral alterations suggestive of lower anxiety or higher impulsiveness in both young and adult animals. The interpretation of lower anxiety and/or higher impulsiveness observed in severely malnourished animals (6\% protein) in the present study is supported by the data frequency of attempts to enter open arms. While wellnourished rats assess the risk of entering the open arms by placing the two front paws in the open arms and returning to the central platform or enclosed arms, severely malnourished animals (M6 groups) spend less time in this assessment and decided, more frequently, to enter open arms. Taken together, these results suggest that severe protein malnutrition for a short period of time during lactation and post-lactation produces a behavioral alteration in the plus-maze in the direction of a lower anxiety or higher impulsiveness. The suggestion of a higher impulsiveness is an interesting one because early malnourished animals exhibited a lower performance in a classical model of behavioral inhibition named DRL (differential reinforcent of low rates), as described by Brioni and Orsingher (1988) and Tonkiss et al. (1990). However, despite the fact that the EPM is widely accepted as a classical animal model of anxiety, it measures exploratory behavior as well, which it in most of the cases in correlated with the indicators of anxiety. Thus, the possibility that the behavioral alterations found in the present study resulted of alterations found in the present study resulted of alterations in the exploratory behavior following protein malnutrition needs further investigation. Nevertheless, as showed in Figure 2, the number of closed arm entries (an well-accepted index of locomotor activity) may indicate similar exploratory behaviors between malnourished and control animals, reinforcing the interpretation of lower anxiety and/or higher impulsiveness.

It is also interesting to observe that a producer of severe malnutrition ( $6 \%$ of protein in the diet) was necessary to produce such alteration $(10 \%$ of protein in the diet) was not sufficient to produce the behavioral alterations caused by the diet containing $6 \%$ protein. The absence of effects of diets containing $10 \%$ protein could be due to the short period of exposure to the diets (lactation period for some groups and from birth to 35 days of age for other groups). This interpretation is in accordance with previous studies in the literature reporting that behavioral alterations after nutritional insult are dependent on the level of malnutrition imposed and the period of exposure to malnutrition (Morgane et al., 1993). Despite the absence of behavioral alterations with diets containing $10 \%$ protein, it was demonstrated that this diet was efficient to produce significant weight deficits. These data suggest that behavioral adaptation to mild protein deficiency in this experimental procedure (EPM) is possible, even in the absence of body weight adaptation.

Significant overall effects of environmental stimulation were observed in all the behavioral categories analyzed in the EPM, showing a lower anxiety of stimulated animals as compared with non-stimulated ones. In addition, we observed a significant diet $\mathrm{x}$ environmental stimulation interaction on the number of attempts to enter arms, and triple interactions (diet $\mathrm{x}$ environmental stimulation $\mathrm{x}$ age) on the number of attempts to enter open arms and on the number of closed arm entries. Theses interactions are especially important in the attempts to enter open arms, showing that environmental stimulation affected the behavior of control and of the $10 \%$ protein groups more than the behavior of the $6 \%$ protein groups. Since the results of environmental stimulation seems to be similar for both attempts to enter open arms and closed arm entries (i.e. increases in the frequency of these behaviors), we may suggest that environmental stimulation produced an overall increase in animal activity during the test in the plus-maze. Increased locomotor activity and open arms exploration in stimulated animals agree with literature studies using the same (Santucci et al., 1994) and other animal models of anxiety (Santucci et al., 1994; Fernández-Teruel et al., 1992; Bodnoff et al., 1987; Rocha and Mello, 1994).

Finally, the present data showing that older animals (35 days of age) are more anxious than younger controls (22 days of age) support previously reported results. It has been demonstrated that anxiety in the elevated plus-maze increases with age at testing time (Imhof et al., 1993). 
However, older $6 \%$ protein malnourished animals did not show increased anxiety as evidenced by a similar number of open arm entries and time spent in those arms as compared with younger animals. These differential effects of nutritional history on the response of older animals produced a significant nutrition $\mathrm{x}$ day interaction indicating that the anxiety did not increase for severely malnourished animals as they turned older. Nutritionally recovered animals (L groups) showed results more similar to those of well-nourished controls. Another possible explanation for the higher anxiety of older animals may lie in the fact these animals were individually reared as compared with animals tested at 22 days of age with their mother and littermates. This lack of social interaction at 35 days of age may contribute to the higher anxiety of these animals in the maze, as indicated by a previous report (Da Silva et al., 1996).

In summary, the present study showed that even a short period of severe protein malnutrition (6\% of protein) produced significant alteration (6\% of protein) produced significant alterations in the behavior of rats in the elevated plus-maze.

These results are similar to those obtained with adult animals tested after prolonged periods of nutritional deficiency and nutritional recovery. In addition, milder protein malnutrition (10\% of protein) was not effective to produce behavioral alterations in this model, although a significant body weight deficit was produce by such a diet. Nutritional recovery from 22 to 35 days of age did not reverse all the alterations produced by early malnutrition, indicating either long-lasting effects of early malnutrition or insufficient time allowed for nutritional recovery in the present experimental protocol.

\section{ACKNOWLEDGEMENTS}

This work was supported by Research Grants 500833/90-7 and 523325/95-9 from CNPq-Brazil and Research Grants 90/3474-8 and 95/9501-2 from FAPESP - Brazil. S.S.A. and L.M.O. were the recipients of Research Fellowships from CNP'-Brazil. T.R.R., P.S.A. and A.F.C. were the recipients of scholarships from CNP'Brazil. The authors thank Dalmo C.P. Nicola for technical assistance.

\section{REFERENCES}

Almeida, S. S., De Oliveira, L. M., \& Graeff, F. G (1991). Early protein malnutrition changes exploration of the elevated plus-maze and reactivity to anxiolytics. Psychopharmacology, 103, 513-518.

Almeida, S. S., Garcia, R. A., \& De Oliveira, L. M. (1993). Effects of early protein malnutrition and repeated testing upon locomotor and exploratory behaviors in the elevated plus-maze. Physiology and Behavior, 54, 749-752.

Almeida, S. S., Garcia, R. A., Ciben, M. M. R., Araujo, M., Moreira, G. M. S., \& De Oliveira, L. M. (1994). The ontogeny of exploratory behaviors in early protein malnourished rats exposed to the elevated plus-maze. Psychobiology, 22, 283-288.
Almeida, S. S., Tonkiss, J., \& Galler, J. R (1996) Prenatal protein malnutrition affects exploratory behavior of female rats in the elevated plus-maze test. Physiology and Behavior, 60, 675-680.

Barnes, R. H. (1976) Dual role of environmental deprivation and malnutrition in retarding intellectual development. American Journal of Clinical Nutrition, 29, 912-917.

Bodnoff, S. R., Suranyi-Cadotte, B., Quirion, R, \& Meaney, M.J. (1987) Postnatal handling reduces novelty-induced fear and increases $[3 \mathrm{H}]$ flunitrazepam binding in rat brain. European Journal of Pharmacology, 144, 105-107.

Brioni, J. D., \& Orsingher, O. A. (1988)Operant behavior and reactivity to the anticonflict effect of diazepam in perinatally undernourished rats. Physiology and Behavior, 44, 193-198.

Da Silva, N. L., Ferreira, V. M., Carobrez, A. P., \& Morato, G.S. (1996) Individual housing from rearing modifies the performance of young rats on the elevated plus-maze apparatus. Physiology and Behavior, 60, 1391-1396.

Denenberg, V. H. (1969) The effects of early experience. In: E.S.E. Hafez (Ed.), The Behavior of domestic Animals (pp. 95-130). London.

Fernández-Teruel, A., Escotihuela, R. M., Núñes., J. F., Gomà, M., Driscoll, P., \& Tobeña, A. (1992). Early stimulation effects on novelty-induced behavior in two psychogenically-selected rat lines with divergent emotionality profiles. Neuroscience Letters, 137, 185188.

Grantham-McGregor, S (1995) A review of studies of the effect of severe malnutrition on mental development. Journal of Nutrition, 125, 2233S-2238S.

Imnhof, J. T., Coelho, M. I., Schimitt, M. L. Morato, G. S., \& Carobrez, A. P (1993) Influence of gender and age on performance of rats in the elevated plus-maze apparatus. Behavioral Brain Reseach, 56, 177-180.

Laino, C. H., Córdoba, N. E., \& Orsingher, O. A. (1993) Perinatally protein-deprived rats and reactivity to anxiolytic drugs on the plus-maze test: An animal model for screening antipanic agents? Pharmacology, Biochemistry and Behavior, 46, 89-94.

Levitsky, D. A., \& Strupp, B. J. (1995) Malnutrition and the brain: changing concepts, changing concerns. Journal of nutrition, 125, 2212S-2220S.

Moreira, G. M. S., Araujo, M., De Oliveira, L. M., \& Almeida, S. S. (1997) The behavior of protein-calorie malnourished rats on the elevated plus-maze test: and ethopharmacological analysis. Psychobiology, 25, 180185.

Morgane, P. J., Austin-LaFrance, R. J., Bronzino, J. D., Tonkiss, K., Diaz-Cintra, S., Cintra, L., Kemper, T., \& Galler, J. R (1993) Prenatal malnutrition and development of the brain. Neuroscience Biobehavioral reviews, 17, 91-128.

Pellow, S., Chopin, P., File, S., \& Briley, M. (1985) Validation open: closed arm entries in an elevated plus-maze as a measure of anxiety in the rat. Journal of Neuroscience Methods, 14, 149-167. 
Renner, J. M., \& Rosenzweig, M. R. (1987) Enriched and Ompoverished Environments: Effects on Brain and Behavior. Springer-Verlag, New York.

Rocha, J. B. T, \& Mello, C. F (1994) Handling during suckling alters rat behavior but does not reverse the deleterious effects of undernutrition on naltrexoneinduced inhibition of exploratory activity. International Journal for Vitamin and Nutrition Research, 64, 152-156.

Rocinholi, L. F., Almeida, S. S., \& De Oliveira, L. M (1997) Response threshold to aversive stimuli in stimulated early protein-malnourished rats. Brazilian Journal of Medical and Biological Research, 30, 407413.

Rodgers, R. J., Cao, B. J., Dalvi, A., \& Holmes, A. (1997) Animal models of anxiety: An ethological perspective. Brazilian Journal of Medical and Biological Research, 30, 289-304.

Santucci, L. B., Daud, M. M., Almeida, S. S., \& De Oliveira, L. M (1994). Effects of early protein malnutrition and environmental stimulation upon the reactivity to Diazepam in two animal models of anxiety. Pharmacology Biochemistry and Behavior, 49(1), 393-398.

Tonkiss, J., Galler, J. R., Formica, R. N., Shukitt-Hale, B., \& Timm, R. R. (1990) Fetal protein malnutrition impairs acquisition of a DRL lask in adult rats. Physiology and Behavior, 48, 73-77. 